\title{
Promoter hypermethylation of the tumor- suppressor genes ITIH5, DKK3, and RASSF1A as novel biomarkers for blood-based breast cancer screening
}

Vera Kloten ${ }^{1}$, Birte Becker ${ }^{1}$, Kirsten Winner ${ }^{1}$, Michael G Schrauder ${ }^{2}$, Peter A Fasching $^{2}$, Tobias Anzeneder $^{3}$, Jürgen Veeck ${ }^{1}$ Arndt Hartmann ${ }^{4}$, Ruth Knüchel ${ }^{1}$ and Edgar Dahl ${ }^{1 *}$

\begin{abstract}
Introduction: For early detection of breast cancer, the development of robust blood-based biomarkers that accurately reflect the host tumor is mandatory. We investigated DNA methylation in circulating free DNA (cfDNA) from blood of breast cancer patients and matched controls to establish a biomarker panel potentially useful for early detection of breast cancer.

Methods: We examined promoter methylation of seven putative tumor-suppressor genes (SFRP1, SFRP2, SFRP5, ITIH5, WIF1, DKK3, and RASSF1A) in cfDNA extracted from serum. Clinical performance was first determined in a test set $(n=261$ sera). In an independent validation set $(n=343$ sera), we validated the most promising genes for further use in early breast cancer detection. Sera from 59 benign breast disease and 58 colon cancer patients were included for additional specificity testing.

Results: Based on the test set, we determined ITIH5 and DKK3 promoter methylation as candidate biomarkers with the best sensitivity and specificity. In both the test and validation set combined, ITIH5 and DKK3 methylation achieved $41 \%$ sensitivity with a specificity of $93 \%$ and $100 \%$ in healthy and benign disease controls, respectively. Combination of these genes with RASSF1A methylation increased the sensitivity to $67 \%$ with a specificity of $69 \%$ and $82 \%$ in healthy controls and benign disease controls, respectively.

Conclusions: Tumor-specific methylation of the three-gene panel (ITIH5, DKK3, and RASSF1A) might be a valuable biomarker for the early detection of breast cancer.
\end{abstract}

\section{Introduction}

Breast cancer remains the most frequently diagnosed cancer and the leading cause of cancer deaths in European women [1]. According to the World Health Organization (WHO), more than 449,000 women in Europe will be diagnosed yearly with breast cancer, comprising approximately $28 \%$ of all cancers in female patients. Localized, early-stage breast cancer has a favorable prognosis, with a 5 -year survival rate of up to $98 \%$. However, the 5 -year survival rate declines to $20 \%$ when the tumor

\footnotetext{
* Correspondence: edahl@ukaachen.de

'Molecular Oncology Group, Institute of Pathology, Medical Faculty of the RWTH Aachen University, Pauwelsstrasse 30, D-52074 Aachen, Germany Full list of author information is available at the end of the article
}

has metastasized [2]. Although clinical examination and ultrasound provide a preliminary screening method, the two most sensitive and specific detection methods to date are mammography and magnetic resonance imaging (MRI). Mammography has become the standard of care in breast cancer screening. Mammograms are useful in that they are reliable and sensitive enough to detect ductal carcinoma in situ (DCIS). Nevertheless, the limitations of mammography are well recognized $[3,4]$, such as the personal discomfort, the poor accuracy in women with dense breast tissue, and a relatively high rate of false positives. Clinically occult early-stage breast cancer is often similar in appearance to a benign breast lesion, resulting in unnecessary subsequent biopsies [3].

\section{Biomed Central}


In addition, more than $10 \%$ of breast tumors are missed by mammography, leading to a sensitivity of $70 \%$ to $91 \%$ [5]. In contrast, MRI requires no breast compression and offers excellent imaging around dense breast tissue. Unfortunately, the high sensitivity (85\% to $100 \%$ ) of MRI is compromised by a high rate of false positives (37\% to $100 \%$ ), which call for unnecessary follow-up examinations and invasive biopsies [6]. Regarding these limitations of mammography and MRI in population-based screening, minimally invasive screening tests are desirable that could complement mammography or MRI, or even stand alone as a primary screening tool. Confidence is growing that the next generation of screening tests will be based on molecular biomarkers present in bodily fluids.

Determination of promoter methylation of tumor-suppressor genes in the DNA of easily accessible bodily fluids, like serum or plasma, is a rapidly growing research field in cancer detection. The principle of DNA methylation markers for early breast cancer detection is based on evidence that growing tumors release significant amounts of circulating free DNA (cfDNA) into the bloodstream through cellular necrosis, apoptosis, or spontaneous release of DNA into the circulation from primary and metastatic tumors $[7,8]$. The diagnostic potential of RASSF1A and $A P C$ promoter methylation in cfDNA from breast cancer patients has been investigated in several studies [9-12]. In particular, RASSF1A methylation of cfDNA predicted the presence of breast cancer with a sensitivity ranging from $15 \%$ to $75 \%$, whereas with $A P C$, methylation sensitivities from $2 \%$ to $47 \%$ were achieved. For either, gene specificity in healthy controls was claimed to be high (90\% to $100 \%)$.

Although several potential DNA methylation biomarkers have been reported, none of these has reached clinical practice. A major limitation to further development for clinical use might have been that these studies analyzed small numbers of breast cancers and matched control specimens, and validations with larger patient cohorts were not pursued [13-15]. Furthermore, investigations of the methylation patterns in cfDNA from non-breast cancers or different benign breast diseases to identify potential specificity issues is lacking in most of these studies. Colon cancer in women is by $60 \%$ less frequent than breast cancer [1] (for example, APC methylation is also detected in cfDNA from colon cancer patients with considerable sensitivity) [16]. Therefore, supposed specific biomarkers are reduced in their overall specificity when analyzing additional serum samples from non-breast tumor patients. In addition, fibroadenoma tumors, the most common benign tumors in women, typically found during the middle and later reproductive years, are a potential source for hypermethylated cfDNA [17], indicating that high specificity in benign disease controls is mandatory to establish a suitable biomarker panel for early breast cancer detection.
In the present study, seven potential breast cancer marker candidates (SFRP1, SFRP2, SFRP5, WIF1, DKK3, $I T I H 5$, and RASSF1A) were studied with regard to early breast cancer detection in serum. These genes have previously shown cancer-specific methylation in breast tissue [18-22]. So far, no studies have considered the promoter methylation of these genes in a large set of breast cancer serum samples, as well as different specificity controls. We examined promoter methylation of these candidate genes in two independent sets with a total of 604 serum samples and 112 matched breast cancer tissues. In a test set $(n=$ 261 sera; $n=112$ tissues), we determined the best candidate markers with the highest specificity in age-matched healthy and benign disease controls. An independent validation set ( $n=343$ sera) was then used to validate the top genes obtained from the test study as reliable detection markers.

\section{Materials and methods \\ Patients}

In total, 604 serum samples were assessed in this casecontrol study. It included samples from patients with all stages of breast cancer ( $n=250$ sera), cancer-free individuals $(n=237$ sera), patients with benign breast disease ( $n=59$ sera), and patients with colon cancer $(n=58$ sera). Importantly, $90 \%$ of the patients in both the test and the validation set had small tumors (pT1 or pT2). Furthermore, asymptomatic women who, based on their family history and/or mutational analysis, were suspected or proven to carry mutations in breast cancer susceptibility genes (BRCA1 and BRCA2) or had a previous breast tumor were not included in our group of healthy controls. An overview of the analyzed serum sets is summarized in Figure 1. A subset of 261 serum and 112 paired breast cancer tissue samples was used as test set, and was obtained from the tumor bank of Euregional comprehensive Cancer Center Aachen (ECCA), now part of the RWTH centralized biomaterial bank (RWTH cBMB). All patients gave informed consent for retention and analysis of their serum for research purposes (local ethical review board of the medical faculty of the RWTH Aachen, ref no. EK-206/09). The validation set consisted of 343 samples, including clinicopathologically matched samples to the test set. Samples of the validation set were obtained from the University Hospital of Erlangen and from Patients' Tumor Bank of Hope (PATH foundation, a research resource for breast cancer biosamples) [23]. Additional controls were collected from individuals with colon cancer, because colon cancer is the second common cancer type in women. In addition, various sera from benign breast disease patients, including fibroadenoma $(n=17)$, desmoid tumors $(n=1)$, benign phyllodes tumors $(n=1)$, mastopathy $(n=33)$, papilloma $(n=5)$, duct ectasia 


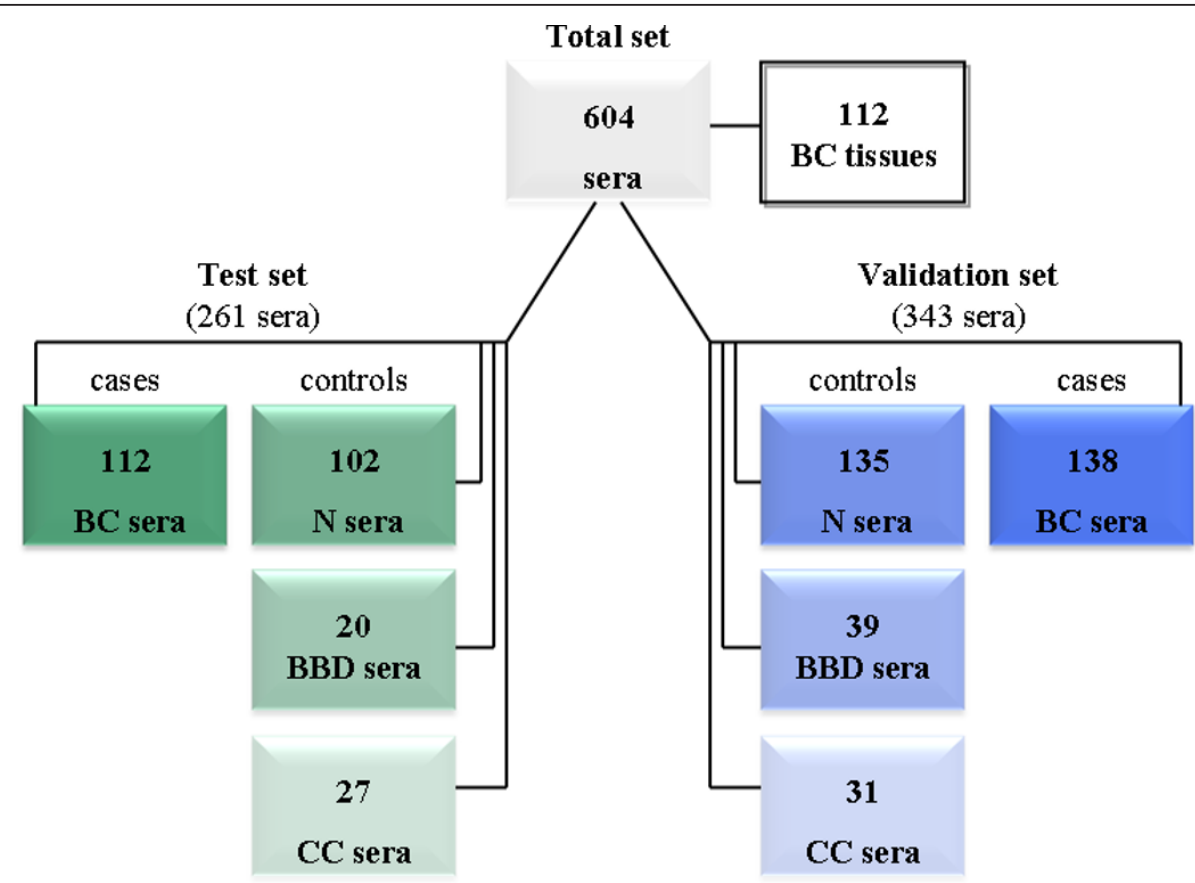

Figure 1 Overview of the analyzed serum samples in two independent sets and paired breast cancer tumor tissues. BBD, benign breast disease; BC, breast cancer; $C C$, colon cancer; $N$, healthy normal.

$(n=1)$, and harmatoma $(n=1)$ were analyzed for additional specificity testing. Additional control samples were obtained from the RWTH cBMB. An overview of the clinical characteristics of the breast cancer patients in the test and validation set is summarized in Table 1. All subjects participating were HIV, HBV, and HCV negative and had no previous history of cancer. Blood from all patients was drawn immediately or up to 2 days after diagnosis and before starting any cancer-specific treatment. All patient samples were collected between the years 2005 and 2012.

Tumor material was snap-frozen in liquid nitrogen directly after surgery. Hematoxylin and eosin-stained sections were prepared for assessment of the percentage of tumor cells, but only samples with $>70 \%$ tumor cells were selected. Blood samples $(10 \mathrm{ml})$ from all study participants were obtained by venipuncture. Samples were immediately centrifuged at 2,000 $g$ for 10 minutes at room temperature, and $1-\mathrm{ml}$ serum aliquots were stored at $-80^{\circ} \mathrm{C}$ until use.

\section{Nucleic acid extraction}

Genomic DNA from breast tumors was isolated by using the QIAamp DNA Mini Kit (Qiagen, Hilden, Germany) according to the manufacturers' recommendations.

CfDNA was extracted from $1 \mathrm{ml}$ serum by using the QIAamp Circulating Nucleic Acid Kit (Qiagen) according to the manufacturer's recommendations, eluted in $35 \mu \mathrm{l}$ of TE buffer, and quantified spectrophotometrically. In the test set, the median quantity of cfDNA in breast cancer serum was $903 \mathrm{ng} \mathrm{DNA} / \mathrm{ml}$ serum (range, 304.5 to $8,291.5$ ) and $889 \mathrm{ng} \mathrm{DNA} / \mathrm{ml}$ serum (range, 297.5 to $1,893.5)$ in healthy controls. In the validation set, the median quantity of $791 \mathrm{ng} \mathrm{DNA} / \mathrm{ml}$ serum (range, 164.5 to $1,680)$ cfDNA was obtained from breast cancer sera, and $833 \mathrm{ng}$ DNA/ml (range, 332.5 to 3,010) from healthy controls. DNA samples were stored at $-80^{\circ} \mathrm{C}$ until use.

\section{DNA bisulfite modification}

The extracted tissue DNA and serum cfDNA was bisulfiteconverted by using the EZ DNA methylation kit (Zymo Research, Orange, CA, USA) as previously described [18].

\section{Methylation-specific polymerase chain reaction (MSP)}

The methylation status of the different genes was determined qualitatively by methylation- specific polymerase chain reaction (MSP) [24] and quantitatively by MethyLight technology [25]. For MSP, bisulfite-converted DNA was amplified by using primer sets specific for unmethylated and methylated promoter sequences in each candidate gene. PCRs were run in a volume of $25 \mu \mathrm{l}$, containing 20 ng bisulfite-modified DNA, $2.5 \mu \mathrm{l} 10 \times$ MSP PCR buffer [26], $1.25 \mu \mathrm{l}$ dNTPs $(25 \mathrm{mM}), 0.5 \mu \mathrm{l}$ sense primer $(10 \mu M)$, $0.5 \mu \mathrm{l}$ antisense primer $(10 \mu M), 1.25$ units GoTaq Flexi DNA polymerase (Promega, Madison, WI, USA) $(0.25 \mu \mathrm{l}$ Taq $+4.75 \mu \mathrm{l} \mathrm{H}_{2} \mathrm{O}$ ), and $14.25 \mu \mathrm{H}_{2} \mathrm{O}$. The PCR profile was $95^{\circ} \mathrm{C}$ for 5 minutes, 38 to 40 cycles at $95^{\circ} \mathrm{C}$ for 30 seconds, primer annealing at $59^{\circ} \mathrm{C}$ to $63^{\circ} \mathrm{C}$ for 30 seconds, $72^{\circ} \mathrm{C}$ for 30 seconds, and a final extension step at $72^{\circ} \mathrm{C}$ for 
Table 1 Clinicopathologic parameters of patients with breast cancer in the test and validation sets

\begin{tabular}{|c|c|c|c|c|c|}
\hline Categorization & Test set $\left(n^{\mathrm{a}}=112\right)$ & $\%$ & Validation set $\left(n^{\mathrm{a}}=138\right)$ & $\%$ & $P$ value $^{\mathrm{b}}$ \\
\hline Age at diagnosis & & & & & 0.327 \\
\hline Median & 60 years (range, $36-87$ years) & & 63 years (range, 33-86 years) & & \\
\hline Menopausal status & & & & & 0.791 \\
\hline Premenopausal & 22 & 19.6 & 21 & 15.2 & \\
\hline Postmenopausal & 90 & 80.4 & 117 & 84.8 & \\
\hline Tumor size ${ }^{c}$ & & & & & 0.337 \\
\hline$\overline{\mathrm{pT} 1}$ & 49 & 43.8 & 67 & 48.6 & \\
\hline pT2 & 51 & 45.5 & 59 & 42.8 & \\
\hline pT3 & 8 & 7.1 & 8 & 5.9 & \\
\hline pT4 & 2 & 1.8 & 2 & 1.4 & \\
\hline Unknown & 2 & 1.8 & 2 & 1.4 & \\
\hline Lymph node status $^{c}$ & & & & & 0.997 \\
\hline pNO & 55 & 49.1 & 77 & 55.8 & \\
\hline pN1 & 38 & 33.9 & 42 & 30.4 & \\
\hline pN2 & 9 & 8.0 & 10 & 7.2 & \\
\hline pN3 & 7 & 6.3 & 6 & 4.3 & \\
\hline Unknown & 3 & 2.7 & 3 & 2.2 & \\
\hline Histologic type & & & & & 0.617 \\
\hline Invasive ductal & 89 & 79.5 & 115 & 83.3 & \\
\hline Invasive lobular & 15 & 13.4 & 17 & 12.3 & \\
\hline Other & 8 & 7.2 & 6 & 4.2 & \\
\hline Tumor grade ${ }^{d}$ & & & & & 0.175 \\
\hline$\overline{G 1}$ & 6 & 5.4 & 14 & 10.1 & \\
\hline G2 & 62 & 55.4 & 76 & 55.1 & \\
\hline G3 & 44 & 39.3 & 48 & 34.8 & \\
\hline Estrogen-receptor status $^{\mathrm{e}}$ & & & & & 0.293 \\
\hline 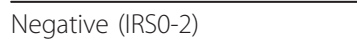 & 22 & 19.7 & 27 & 19.5 & \\
\hline Positive (IRS3-12) & 84 & 75.0 & 109 & 78.9 & \\
\hline Unknown & 6 & 5.4 & 2 & 1.4 & \\
\hline Progesterone-receptor status $^{\mathrm{e}}$ & & & & & 0.112 \\
\hline Negative (IRSO-2) & 30 & 26.8 & 39 & 28.2 & \\
\hline Positive (IRS3-12) & 76 & 68.0 & 96 & 69.3 & \\
\hline Unknown & 6 & 5.4 & 3 & 2.2 & \\
\hline${\text { HER2 } \text { status }^{f}}$ & & & & & 0.112 \\
\hline Negative $(0 ; 1+; 2+)$ & 90 & 80.4 & 114 & 82.6 & \\
\hline Positive (3+) & 14 & 12.5 & 20 & 14.9 & \\
\hline Unknown & 8 & 7.1 & 4 & 2.9 & \\
\hline
\end{tabular}

${ }^{a}$ Only female patients with primary, unilateral, invasive breast cancer were included. ${ }^{\mathrm{b}}$ Fisher Exact test at a two-sided significance level of 0.05 . ${ }^{\mathrm{C}}$ According to TNM classification by Sobin and Wittekind [41]. ${ }^{\mathrm{d}}$ According to Bloom and Richardson, as modified by Elston and Ellis [42]. ${ }^{\mathrm{e} I R S}$, immunoreactive score according to Remmele and Stegner [43]. ' Overexpression for the HER2/neu gene was diagnosed analogous to the threshold of the DAKO-Score system based on IHC assay. Percentages may not sum to $100 \%$ because of rounding.

10 minutes. MSP primer sequences and annealing temperatures are listed in Additional file 1. PCR amplificates were electrophoresed on 3\% agarose gels and evaluated under ultraviolet light. Universal bisulfite-converted polymethylated and unmethylated DNA (Epi Tect Control DNA Set, Qiagen) served as positive controls, and $\mathrm{H}_{2} \mathrm{O}$ and genomic unmodified DNA were included as negative controls in each run.

\section{Quantitative methylation-specific polymerase chain reaction (qMSP)}

Bisulfite-modified DNA was used as template for fluorescence-based real-time PCR, as previously described [25]. Amplification reactions were carried out in triplicate in a volume of $25 \mu \mathrm{l}$ containing $20 \mathrm{ng}$ bisulfite-modified serum DNA, $12.5 \mu$ IQ Supermix (Biorad, Munich, Germany), $0.75 \mu \mathrm{l}$ sense primer $(10 \mu \mathrm{M}), 0.75 \mu \mathrm{l}$ antisense primer 
(10 $\mu M), 0.5 \mu \mathrm{l}$ probe $(10 \mu M)$, and $10.5 \mu \mathrm{l} \mathrm{H}_{2} \mathrm{O}$. Primers and probes were designed specifically to amplify bisulfiteconverted DNA for the genes of interest (DKK3, ITIH5, and $R A S S F 1 A$ ) and the reference housekeeping gene $(G A P D H)$ to normalize for input DNA. Amplifications were carried out by using the following profile: $95^{\circ} \mathrm{C}$ for 10 minutes, 40 to 50 cycles at $95^{\circ} \mathrm{C}$ for 15 seconds, and primer annealing at $58^{\circ} \mathrm{C}$ to $66^{\circ} \mathrm{C}$ for 30 seconds. QMSP primer sequences and annealing temperatures are listed in Additional file 2.

Amplifications were performed in an iCycler iQ5 (BioRad). Each plate included positive controls for the methylated sequence (in vitro methylated human leukocyte DNA) and unmethylated sequence (human leukocyte DNA from a healthy donor), as well as multiple water blanks. Primer binding sites of the qMSP assays were located in the same genomic promoter region as primers used for MSP analyses.

\section{Analytic performance of the blood-based qMSP assays} Leukocyte DNA from healthy individuals was methylated with SssI (CpG) methyltransferase (New England Biolabs, Beverly, MA, USA) to generate completely methylated DNA. Serial dilutions (500 ng to $0.025 \mathrm{ng}$ ) of this DNA were used to construct a calibration curve for each plate. Control DNA for serial dilutions was diluted before bisulfite conversion. All analyzed samples were within the different assays range of sensitivity and reproducibility, based on amplification of internal reference standard (cycle threshold $\left(\mathrm{C}_{\mathrm{T}}\right)$ value for $G A P D H$ of 32 or less). The gene of interest was called methylated if the $C_{T}$ of at least two of three PCR replicates for each specimen had a value of less than 45 cycles. Genes of interest were considered unmethylated if $C_{\mathrm{T}}$ was not measurable or was $\geq 45.0$ and the GAPDH $\mathrm{C}_{\mathrm{T}}$ was $\geq 33$ cycles. The amount of methylated DNA (percentage of methylated reference, PMR) at a specific locus was calculated by dividing the GENE/GAPDH ratio of a sample by the GENE/GAPDH ratio of SsSI-treated human leukocyte DNA and multiplying by 100 [25]. Additionally, analytic performance of the DKK3, ITIH5, and RASSF1A assay was determined by using the in vitro methylated human leukocyte DNA added in definite concentrations (500 ng to $0.01 \mathrm{ng}$ ) to $1 \mathrm{ml}$ disease-free human serum. Next, the added methylated DNA was isolated and bisulfite-treated as mentioned earlier. The detection limit of DKK3 and RASSF1A methylation at the specimen level was $50 \mathrm{pg} / \mathrm{ml}$, and of ITIH5 methylation, $100 \mathrm{pg} / \mathrm{ml}$

\section{Statistical analysis}

Statistical analyses were performed by using SPSS 17.0 (SPSS, Chicago, IL, USA) and GraphPad Prism 5.0 (GraphPad Software Inc., La Jolla, CA, USA). P values of
$<0.05$ were considered significant. Two-sided Fisher Exact tests were performed to compare clinicopathologic factors between cohorts, and to correlate clinicopathologic parameters with the methylation values of the candidate genes in the test and validation sets. A MannWhitney $U$ test was used to detect significantly differential methylation levels between serum of age-matched healthy women, benign breast diseases, sera from colon cancers, and breast cancer. Mean methylation values of the three-gene panel were visually compared by using scatterplots of the log-transformed PMR values. Receiver-operating-characteristics (ROC) curves were calculated to evaluate the diagnostic performance of different marker combinations [27].

\section{Results}

Determination of the best-performing genes for a breast cancer blood test with qualitative MSP

We initially assessed promoter methylation of SFRP1, SFRP2, SFRP5, ITIH5, DKK3, and WIF1 in 112 paired breast cancer tissue and serum samples by using qualitative MSP. The majority of genes methylated in cfDNA were also methylated in tissue DNA, whereas methylation of tissue DNA was less frequently retrieved in cfDNA. A significant positive correlation between promoter methylation of DKK3 $(P=0.003)$ and ITIH5 $(P=0.007)$ in paired tissue DNA and serum cfDNA was found (see Additional file 3). SFRP2 was methylated in four cases, and both SFRP1 and ITIH5 in two cases of cfDNA, with no corresponding methylation in the paired-tissue DNA. In general, methylation frequencies of ITIH5, WIF1, and $D K K 3$ in cfDNA were at least $36 \%$ compared with that of tissue DNA, whereas SFRP1, SFRP2, and SFRP5 exhibited just $9 \%$ to $24 \%$ of cfDNA methylation compared with the methylation frequency in paired tissue DNA (Table 2).

Next, we investigated methylation of the six candidate genes in 102 age-matched healthy controls and 47 additional disease controls. An overview of the methylation frequencies in the studied serum samples of the test set is given in Tables 2 and 3. Based on the methylation frequencies, we defined for the most suitable genes for a clinical assay the following criteria: methylated in $\leq 7 \%$ of serum samples from healthy controls and benign disease controls, $\leq 20 \%$ in colon cancer serum samples, and $\geq 20 \%$ in serum samples from breast cancer patients. On the basis of the defined criteria, SFRP5 methylation (8.25\%) was too infrequent in breast cancer sera, and thus excluded from further specificity analyses. Similarly, SFRP1 and SFRP2 showed high methylation rates in healthy controls and benign disease samples (Table 3), and thus were excluded.

Finally, WIF1 was excluded because this gene exhibited an abundant methylation rate $(25 \%)$ in serum samples from benign breast diseases. Additional specificity testing 
Table 2 Detection of aberrant gene promoter methylation in paired samples (serum and tumor) in the test set

\begin{tabular}{|c|c|c|c|c|}
\hline \multirow[b]{2}{*}{ Gene } & \multicolumn{2}{|c|}{$\begin{array}{l}\text { Sensitivity in } \\
\text { breast cancer serum }\end{array}$} & \multicolumn{2}{|c|}{$\begin{array}{l}\text { Sensitivity in } \\
\text { breast cancer tissue }\end{array}$} \\
\hline & $\begin{array}{l}\text { Methylation } \\
\text { Positive }\end{array}$ & $\%$ & $\begin{array}{l}\text { Methylation } \\
\text { positive }\end{array}$ & $\%$ \\
\hline ITIH5 & 27 of 112 & 24 & 81 of 112 & 72 \\
\hline DKK3 & 37 of 112 & 33 & 97 of 112 & 87 \\
\hline WIF1 & 39 of 112 & 35 & 108 of 112 & 96 \\
\hline SFRP1 & 12 of 112 & 11 & 89 of 111 & 79 \\
\hline SFRP2 & 21 of 112 & 19 & 90 of 112 & 80 \\
\hline SFRP5 & 9 of 112 & 8 & 104 of 110 & 93 \\
\hline$D K K 3 / I T I H 5^{a}$ & 46 of 112 & 41 & 105 of 112 & 94 \\
\hline
\end{tabular}

${ }^{\mathrm{a}}$ Either gene methylated.

in 27 colon cancer samples revealed moderate methylation frequencies in all candidate markers with the exception of DKK3 (Table 4). Two genes, ITIH5 and DKK3, met our defined criteria, and were highly specifically unmethylated in sera from healthy women and those affected with benign disease, as well as sera from nonbreast tumors. In addition, only DKK3 and ITIH5 methylation showed a significant concordance in tumor tissue and paired serum specimens. The combination of $D K K 3$ and ITIH5 (either gene methylated) substantially improved sensitivity and specificity, which predicts breast cancer with a sensitivity of $41 \%$ and a specificity of $93 \%$, $100 \%$, and $88 \%$ in age-matched healthy control samples, benign breast disease, and colon cancer samples, respectively. Considering all control samples, including sera from patients with colon cancer, benign breast disease, and healthy controls, yielded a specificity of 93\% (139 of 149) with combined DKK3 and ITIH5 methylation.

\section{Detection of breast cancer in an independent validation} set by using ITIH5, DKK3, and RASSF1A

To confirm the clinical performance of $D K K 3$ and ITIH5 methylation, we used serum samples from an independent patient set. In the validation data analysis, 138 breast cancer samples, 135 samples from age-matched healthy controls, and 70 additional disease controls were analyzed. To increase the analytic sensitivity and to yield a higher reproducibility [28,29] we analyzed the validation set with qMSP. Primer binding sites of both the MSP and the qMSP assays were located in the same genomic promoter region but did not cover identical CpG dinucleotides. Nevertheless, methylation frequencies of the analyzed genes in the test and the validation sets were very highly similar, independent of the technology applied. To study the correlation between methylation obtained with MSP and qMSP, serum samples of breast cancer patients of the validation set, including negative and positive cases, were reexamined with qualitative MSP. A significant positive correlation for both ITIH5 $(P=0.040)$ and DKK3 $(P=$ $0.033)$ promoter methylation between both technologies was found.

Methylation of $D K K 3$ was present in serum from two (1.5\%) of 135 matched control subjects and 41 (29.7\%) of 138 breast cancer patients $(P<0.0001)$. In addition, specificity in benign disease controls was high (all 39 (100\%) samples were unmethylated). ITIH5 was methylated in seven (5.2\%) of 135 healthy controls, in one (2.6\%) of 39 benign controls, and 19 (13.8\%) of 138 breast cancer samples. The combination of $D K K 3$ and ITIH5 methylation revealed a sensitivity of $39.9 \%$ (55 of 138) for the detection of breast cancer and a specificity of $93.3 \%$ (126 of 135) and of $97.4 \%$ (38 of 39) in healthy controls and benign disease controls $(P<0.0001)$, respectively. In serum samples from patients with colon cancer, $D K K 3$ was detected in seven (22.6\%) of 31 , whereas ITIH5 was present in nine (29\%) of 31 cases (Table 4).

To improve the sensitivity of the panel, we combined $D K K 3$ and ITIH5 with the potential biomarker RASSF1A. RASSF1A methylation was significantly different between serum of breast cancer patients (64 (47.1\%) of 136$)$, and both healthy controls (35 (25.9\%) of 135)

Table 3 Sensitivity and specificity of serum-based detection of aberrantly methylated genes in the test set

\begin{tabular}{|c|c|c|c|c|c|c|}
\hline \multirow[b]{2}{*}{ Gene } & \multicolumn{2}{|l|}{$\begin{array}{l}\text { Sensitivity in } \\
\text { breast cancer }\end{array}$} & \multicolumn{2}{|c|}{$\begin{array}{l}\text { Specificity in } \\
\text { healthy controls }\end{array}$} & \multicolumn{2}{|c|}{$\begin{array}{l}\text { Specificity in } \\
\text { benign breast diseases }\end{array}$} \\
\hline & $\begin{array}{l}\text { Methylation } \\
\text { positive }\end{array}$ & $\%$ & $\begin{array}{l}\text { Methylation } \\
\text { negative }\end{array}$ & $\%$ & $\begin{array}{l}\text { Methylation } \\
\text { negative }\end{array}$ & $\%$ \\
\hline ITIH5 & 27 of 112 & 24 & 96 of 102 & 94 & 20 of 20 & 100 \\
\hline DKK3 & 37 of 112 & 33 & 101 of 102 & 99 & 20 of 20 & 100 \\
\hline WIF1 & 39 of 112 & 35 & 97 of 102 & 95 & 15 of 20 & 75 \\
\hline SFRP1 & 12 of 112 & 11 & 92 of 102 & 90 & 17 of 20 & 85 \\
\hline SFRP2 & 21 of 112 & 19 & 90 of 102 & 88 & 18 of 20 & 90 \\
\hline SFRP5 & 9 of 112 & 8 & n.d. & & n.d. & \\
\hline DKK3/ITIH $5^{\mathrm{a}}$ & 46 of 112 & 41 & 95 of 102 & 93 & 20 of 20 & 100 \\
\hline
\end{tabular}

${ }^{\mathrm{a}}$ Either gene methylated. n.d., not done. 
Table 4 Additional specificity testing of aberrantly methylated genes in colon cancer in the test and validation sets

\begin{tabular}{lllll}
\hline & \multicolumn{4}{l}{ Specificity in colon cancer } \\
\cline { 2 - 5 } & Test set & \multicolumn{3}{l}{ Validation set } \\
\hline Gene & $\begin{array}{l}\text { Methylation } \\
\text { negative }\end{array}$ & $\%$ & \multicolumn{1}{l}{$\begin{array}{l}\text { Methylation } \\
\text { negative }\end{array}$} & $\%$ \\
\hline DKK3 & 27 of 27 & $\mathbf{1 0 0}$ & 24 of 31 & $\mathbf{7 7}$ \\
ITIH5 & 24 of 27 & $\mathbf{8 9}$ & 22 of 31 & $\mathbf{7 1}$ \\
WIF1 & 23 of 27 & $\mathbf{8 5}$ & n.d. & \\
SFRP1 & 16 of 22 & $\mathbf{7 3}$ & n.d. & \\
SFRP2 & 22 of 26 & $\mathbf{8 5}$ & n.d. & \\
SFRP5 & n.d. & & n.d. & \\
RASSF1A & n.d. & & 13 of 31 & $\mathbf{4 2}$ \\
DKK3/ITIH5 ${ }^{\text {a }}$ & 24 of 27 & $\mathbf{8 8}$ & 16 of 31 & $\mathbf{5 2}$ \\
Three-gene panel & n.d. & & 6 of 31 & $\mathbf{1 9}$ \\
\hline
\end{tabular}

${ }^{\mathrm{a}}$ Either gene methylated. n.d., not done.

$(P=0.0035)$ and benign disease controls (six (15.4\%) of $39 ; P=0.0013)$. The examination of 31 additional samples from patients with colon cancer indicated low specificity of RASSF1A methylation (42\%) in cfDNA (Table $4)$. Figure 2 illustrates the distribution of mean PMR values for the three-gene panel with ITIH5, DKK3, and RASSF1A. A significant $(P=0.040)$ positive correlation of the methylation status also was obtained with MSP and qMSP in 12 samples (six negative and seven positive cases) of the validation set.

Next, we performed ROC curve analysis for multiple marker combinations to determine both sensitivity and

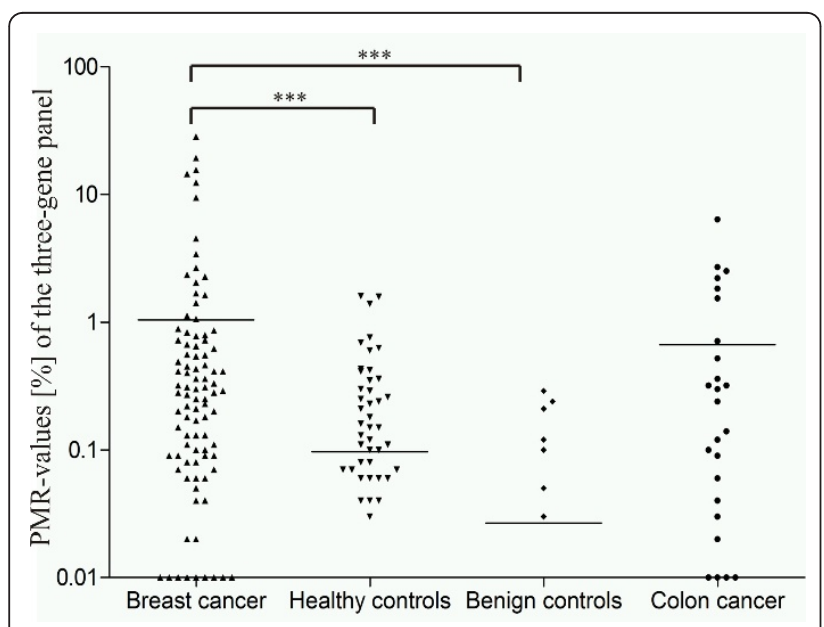

Figure 2 The biomarker panel including ITIH5, DKK3, and RASSF1A enables significant discrimination of breast cancer sera from various control conditions. Scatterplot illustrating the mean PMR values of the three-gene panel in the independent validation set. Combination of DKK3 and ITIH5 with RASSF1A increased the sensitivity to $67 \%$ (92 of 138) with a specificity of $69 \%$ (93 of 135) and 82\% (32 of 39) in healthy and benign disease controls, respectively. ${ }^{* * *} P<0.0001$.

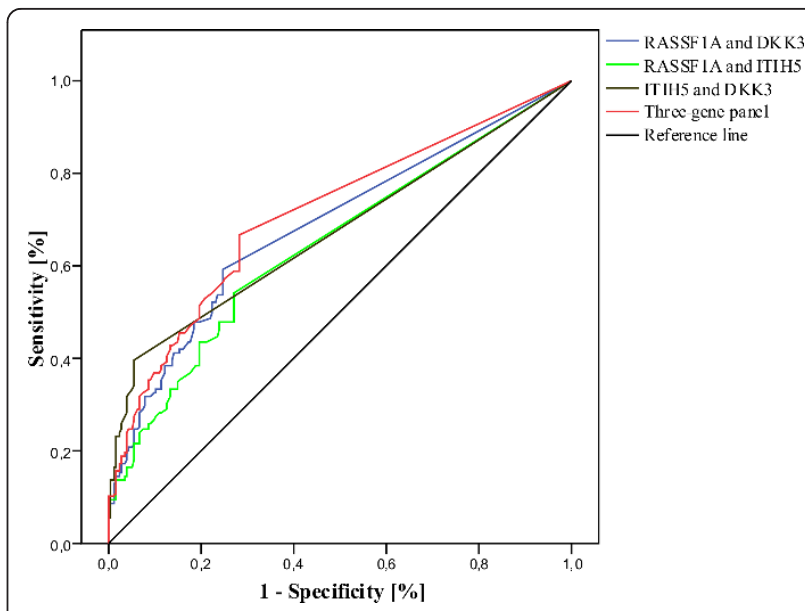

Figure 3 ROC-curve analysis of the three-gene panel in control samples including age-matched healthy and benign disease controls. ROC curves were established for different biomarker combinations to determine a cutoff value. A cutoff value of $0.085 \%$ methylation was defined for positive detection of disease; the specificity of the panel increased to $80.5 \%$ with a sensitivity of $51.4 \%$. ROC analysis revealed an area under the curve (AUC) of 0.712 (95\% Cl, 0.653 to 0.770$)$.

specificity in breast cancer and control samples and to calculate the optimal threshold value for the three-marker panel (Figure 3). According to this analysis, the three-marker panel can discriminate between breast cancer patients and women without breast cancer with a sensitivity of $67 \%$ and a specificity of $69 \%$ (AUC, 0.697 (95\% CI, 0.634 to 0.759$)$ ). Additionally, the three-marker panel allowed distinguishing breast cancer patients from women with a benign breast disease with high specificity (82\%; AUC, 0.765 (95\% CI, 0.692 to 0.839$)$ ). The combination of healthy and benign controls revealed a specificity of the three-marker panel of 72\% (AUC, 0.712 (95\% CI, 0.653 to 0.770$)$ ). Combinations of different markers were examined to maximize specificity and sensitivity. The best combination remained with all three genes (Table 5). Defining a cut-off value for the three-gene panel of $0.085 \%$ for positive detection of methylation (and thus disease), the panel distinguished between breast cancer and both healthy and benign controls with a sensitivity of $51.4 \%$ and a specificity of $80.5 \%$.

\section{Correlation of ITIH5, DKK3, and RASSF1A methylation with} clinicopathologic parameters

The methylation status of ITIH5, DKK3, and RASSF $1 A$ in breast cancer tissue DNA and serum cfDNA in both the test and validation sets was analyzed for association with known clinicopathologic characteristics, including age at diagnosis, tumor grade, tumor size, node status, hormone-receptor status, and menopausal status. Detection of ITIH5, DKK3, and RASSF1A methylation in the test 
Table 5 Sensitivity and specificity of breast cancer detection with different marker combinations

\begin{tabular}{|c|c|c|c|c|c|c|c|c|}
\hline \multirow[b]{2}{*}{ Gene $^{a}$} & \multicolumn{2}{|l|}{$\begin{array}{l}\text { Sensitivity in } \\
\text { breast cancer }\end{array}$} & \multicolumn{2}{|c|}{ Specificity in healthy and benign breast disease controls } & \multirow[t]{2}{*}{$P$ value $^{\mathrm{b}}$} & \multirow[t]{2}{*}{ AUC $(95 \% \mathrm{Cl})$} & \multirow{2}{*}{$\begin{array}{l}\text { PPV } \\
\%\end{array}$} & \multirow{2}{*}{$\begin{array}{l}\text { NPV } \\
\%\end{array}$} \\
\hline & $\begin{array}{l}\text { Methylation } \\
\text { positive }\end{array}$ & $\%$ & $\begin{array}{l}\text { Methylation } \\
\text { negative }\end{array}$ & $\%$ & & & & \\
\hline $\begin{array}{l}\text { RASSFIA } \\
\text { ITIH5 }\end{array}$ & 75 of 138 & 54 & 127 of 174 & 73 & $7.8 \times e^{-6}$ & $0.647(0.585-0.709)$ & 61 & 67 \\
\hline $\begin{array}{l}\text { RASSF1A } \\
\text { DKK3 }\end{array}$ & 82 of 138 & 59 & 131 of 174 & 75 & $1.6 \times \mathrm{e}^{-8}$ & $0.686(0.626-0.747)$ & 66 & 70 \\
\hline $\begin{array}{l}\text { DKK3 } \\
\text { ITIH5 }\end{array}$ & 55 of 138 & 40 & 164 of 174 & 94 & $1.6 \times \mathrm{e}^{-7}$ & $0.673(0.611-0.735)$ & 85 & 66 \\
\hline $\begin{array}{l}\text { RASSF1A } \\
\text { DKK3 } \\
\text { ITIH5 }\end{array}$ & 92 of 138 & 67 & 125 of 174 & 72 & $1.3 \times \mathrm{e}^{-10}$ & $0.712(0.653-0.770)$ & 65 & 73 \\
\hline
\end{tabular}

${ }^{a}$ Either gene methylated. ${ }^{b}$ Fisher Exact test at a two-sided significance level of 0.05 . AUC, area under the curve; $\mathrm{Cl}$, confidence interval; NPV, negative predictive value; PPV, positive predictive value.

and the validation sets was independent of patient age $(P$ $>0.05)$. However, in the test set, sensitivity of $D K K 3$ and ITIH5 methylation and sensitivity of the combined methylation of DKK3/ITIH5 was more frequent in premenopausal women. In the validation set, methylation frequency of either $D K K 3$, or methylation of the gene combination DKK3/ITIH5 or methylation of the threegene panel was also increased in premenopausal women, whereas the methylation frequency of RASSF1A was more frequent in the postmenopausal subgroup. Area under the curve (AUC) values were improved in premenopausal women (see Additional file 4). Furthermore, statistical investigations of the validation set revealed a significant association of $D K K 3$ cfDNA methylation $(P=0.034)$ and cfDNA methylation of the DKK3 and ITIH5 gene combination $(P=0.007)$ with smaller tumors (pT1-2).

\section{Discussion}

In this study, we determined the performance of a bloodbased PCR assay for methylated cfDNA of seven potential biomarkers in two independent serum sets with a total of 604 serum and 112 paired tumor tissue samples. Previous studies showed the involvement of the candidate genes in signal transduction of the WNT pathway (SFRP1, SFRP2, SFRP5, DKK3, and WIF1) [19,20,22], invasion and metastasis (ITIH5) (18), and regulation of apoptotic and cell-cycle checkpoint pathways (RASSF1A) [30], suggesting a role in breast carcinogenesis. The potential use of these genes, except RASSF1A, as blood-based biomarkers for breast cancer was not investigated previously. However, the high methylation frequencies previously described for these genes in breast tumor tissue suggested their potential feasibility for early breast cancer detection in cfDNA. This is the first study aiming to develop a blood-borne PCR assay to detect breast cancer by using two independent series of breast cancer serum samples, thus composing the largest sample collection analyzed for serum-based cfDNA methylation markers.

Methylation changes in carcinogenesis are often heterogeneous, and still no single gene has been found to be methylated in every breast cancer specimen. Furthermore, in most studies investigating methylation levels of only single genes, the sensitivity was low [31]. Therefore, it is considered advantageous to use a panel of genes for breast cancer screening procedures. Recent studies have reported a range of potential gene panels, including the most frequently methylated genes in human breast cancer [11,12,32-34]. In agreement with Van de Voorde et al. [31], most of these potential biomarkers have been analyzed in relatively small patient cohorts, and further validation in larger-scaled patient and age-matched healthy cohorts was not pursued. Furthermore, the frequent lack of ROC analyses in most biomarker studies may result in misinterpretation of the analyzed data [31]. Because of the comparative analysis of 112 paired breast cancer tumor tissues and serum samples, as well as the investigation of a strong and realistic cohort of control samples in our study, we were able to define a biomarker panel with the best values for breast cancer specificity first in a test set. ITIH5 and $D K K 3$ proved to be candidate genes showing a significant correlation of the methylation pattern in paired tumor tissue DNA and cfDNA. Concordance of the methylation pattern found in tissue and serum specimens indicates the potential utility of blood-based detection of breast cancer. Furthermore, ITIH5 and DKK3 methylation achieved $40 \%$ sensitivity with a high specificity in healthy and benign disease controls. In an independent validation set, DKK3 and ITIH5 were further validated in combination with the known biomarker RASSF1A to increase sensitivity of the panel. Indeed, the combination of $D K K 3$ and ITIH 5 with RASSF $1 A$ increased sensitivity from $40 \%$ to $67 \%$, but specificity of RASSF1A in healthy controls was quite low (100 (74\%) of 135), resulting in a reduction of 
specificity from $93 \%$ to $69 \%$ with the three-marker panel. The combination of healthy and benign controls increased specificity of the three-gene panel to $72 \%$. Recent publications reported RASSF1A methylation frequencies of $32 \%$ to $75 \%$ in cfDNA of breast cancer patients, in line with our data from the validation set (sensitivity of 46\%) [30]. In particular, Brooks et al. [12] investigated RASSF1A promoter methylation in 50 breast cancer serum samples, 100 healthy, and 50 benign breast disease controls. Sensitivity of RASSF1A was much lower (22\%) than in our study, whereas specificity in healthy controls was slightly higher. However, specificity of RASSF1A was lower in our study compared with that in other publications [10,34]. This may be due to the examination of a larger set of agematched healthy control samples compared with these studies. The potential biomarkers DKK3 and ITIH5 seem to be more breast cancer specific ( $94 \%$ to $99 \%$ ) but less sensitive (14\% to $33 \%)$ in both the test and the validation sets. Nevertheless, $D K K 3$ promoter methylation could exhibit the feasibility to detect cfDNA methylation of smaller tumors (pT1-2), which also remains valid in combination with ITIH5. ROC analysis of cfDNA methylation of pT1-2 tumors increased the sensitivity of the DKK3 and ITIH5 gene combination in the validation set from $40 \%$ to 43\% (AUC, 0.688 (95\% CI, 0.624 to 0.752 )), which might indicate a potential benefit of DKK3 and ITIH5 for the early detection of breast cancer. However, the validation set comprised only 9\% pT3-4 tumors, so further studies are needed. Additionally, DKK3 and ITIH5 specificity in colon cancer cfDNA is much higher in comparison to RASSF $1 A$, indicating the eligibility of DKK3 and ITIH5 as potential breast cancer biomarkers.

Regarding mammography, with a sensitivity of $70 \%$ and a specificity of $>85 \%$, a reliable biomarker panel for the early detection of breast cancer in cfDNA has to accomplish comparable values. However, sensitivity of mammography declines drastically in patients with dense breast tissue [35], and additionally, mammographic density is a strong risk factor for breast cancer [36-38]. We hypothesize that DKK3 and ITIH5 may be valuable biomarkers for the blood-based detection of breast cancer in patients with dense breast tissue because of their high specificity in the control specimens. Prospectively, DKK3 and ITIH5 methylation analyses may be used in supplement to mammography, the sensitivity of which is low in patients with dense breast tissue. With ROC curve analysis, we examined $D K K 3, I T I H 5$, and also RASSF1A methylation with regard to sensitivity and specificity in pre- and postmenopausal women. Interestingly, in the validation set, methylation of either $D K K 3$, or methylation of the DKK3/ITIH5 gene combination or methylation of the three-gene panel is more frequent in premenopausal women, whereas RASSF1A methylation is increased in postmenopausal women. In the validation set, ROC analysis of cfDNA methylation of premenopausal women revealed a higher sensitivity (52\%) of the DKK3 and ITIH5 gene combination with a specificity of $100 \%$ (AUC, 0.762 (95\% CI, 0.611 to 0.913$)$ ), whereas the DKK3 and ITIH5 gene combination exhibited a sensitivity of $36 \%$ with a specificity of $92 \%$ (AUC, 0.647 (95\% CI, 0.575 to 0.718$)$ ) in postmenopausal women. These results might indicate a pronounced benefit of DKK3 and ITIH5 for the early detection of breast cancer in premenopausal women. However, the premenopausal subgroup in both test and validation sets comprised only $15 \%$ to $20 \%$ of cases, so further studies are needed to confirm this finding.

In summary, the three-marker panel with ITIH5, $D K K 3$, and RASSF1A exhibits significantly increased levels of methylation in serum cfDNA from breast cancer patients compared with both age-matched healthy women and women with a benign breast disease. According to our data, RASSF1A promoter methylation is not an ideal biomarker for early breast cancer detection because it shows a high frequency of methylation in cfDNA derived from sera of healthy individuals. However, although $D K K 3$ and ITIH5 are highly specific in healthy and benign control samples, sensitivity of the potential biomarkers is limited.

Our next goal is to discover and characterize more potential biomarkers for early breast cancer detection with a quality comparable to that of ITIH5 and DKK3 promoter methylation. In addition, other approaches like investigations of copy-number variations (CNVs), loss of heterozygosity $(\mathrm{LOH})$, or point mutations in cfDNA could be used to improve the sensitivity of the two-gene combination. A study by Shaw et al. [39] investigated CNVs and $\mathrm{LOH}$ in cfDNA of breast cancer patients and matched controls and demonstrated different potential gene targets that distinguish between patients with primary breast cancer and healthy controls. It is conceivable that DKK3 and ITIH5 sensitivity could be improved through the additional investigation of CNVs of genes like, for example, MAT1 or JAG2. Another way to improve our approach could be the additional analysis of gene mutations in cfDNA (such as PIK3CA or TP53). Board et al. [40] investigated the potential utility of cfDNA as a source for PIK3CA mutation detection in patients with breast cancer. PIK3CA mutations were detected in 13 (28\%) of 46 plasmaderived and 10 (21\%) of 46 serum-derived cfDNA samples from metastatic breast cancer patients. Interestingly, no PIK3CA mutations were detected in cfDNA from localized breast cancers $(n=30)$. Altogether, this could allow establishing a biomarker panel offering a sensitivity and specificity comparable to that of mammography examination. Of importance, such a blood-borne screening test would be more convenient for the patient and less expensive for the health-care system. 


\section{Conclusions}

Quantifying promoter methylation of putative tumorsuppressor genes in circulating free DNA (cfDNA) of bodily fluids, like serum, is a rapidly growing research topic for early cancer detection. However, in the breast cancer field, none of the reported biomarkers has reached clinical application, mainly because of the small numbers of breast cancer and matched control specimens analyzed. In the current study, seven potential biomarkers were evaluated in two independent serum sets $(n=604)$. Promoter methylation of the DKK3/ITIH5 gene combination allowed significant discrimination of breast cancer sera from various control conditions. Moreover, these biomarkers showed the feasibility of detecting cfDNA methylation even in smaller tumors and in premenopausal women. A simple and noninvasive blood-borne screening test could complement image-driven screening technologies like mammography or magnetic resonance imaging (MRI) in early breast cancer detection.

\section{Additional material}

Additional file 1: Sequences for the MSP primer and performing conditions. The table shows the primer sequences of the genes analyzed with MSP, the performing conditions, and the product size.

Additional file 2: Sequences for the MethyLight primer and performing conditions. The table shows the primer sequences of the genes analyzed with qMSP, the performing conditions, and the product size.

Additional file 3: Correlation of the methylation level in tissue DNA and cfDNA in paired breast cancer samples. This table provides the correlation and $P$ values between DKK3 and ITIH5 promoter methylation in paired breast cancer tissue DNA and serum cfDNA.

Additional file 4: Sensitivity and specificity of breast cancer detection in pre- and postmenopausal women in the test and validation sets. This table provides sensitivity and specificity of $1 \mathrm{TIH} 5$, DKK3, and RASSF1A methylation in pre- and postmenopausal women in the test and validation sets. In addition, area under the curve (AUC) values for all biomarker candidates are shown in these two strata.

\section{Abbreviations}

$A P C$ : adenomatous polyposis coli; $A \cup C$ : area under the curve; $C B M B$ : centralized biomaterial bank; cfDNA: circulating-free DNA; $C_{T}$ : cycle threshold; DCIS: ductal carcinoma in situ; DNA: deoxyribonucleic acid; DKK3: Dickkopf 3; GAPDH: glyceraldehyde-3-phosphate dehydrogenase; HBV: human hepatitis B virus; HCV: human hepatitis C virus; HIV: human immunodeficiency virus; ITIH5: inter-alpha-trypsin inhibitor chain 5; MSP: methylation-specific PCR; PATH: Patients' Tumor Bank of Hope; PCR: polymerase chain reaction; PMR: percentage of methylated reference; RASSF1A: Ras association domain family member 1A; ROC: receiver operating characteristic; SFRP1: secreted frizzledrelated protein 1; SFRP2: secreted frizzled-related protein 2; SFRP5: secreted frizzled-related protein 5; WIF1: Wnt inhibitory factor 1.

\section{Authors' contributions}

$V K, R K$, and ED participated in the design of the study. VK, BB, KW, MGS, PAF, $T A, J V$, and $A H$ carried out the experimental data acquisition. VK, BB, MGS, PAF, JV, and ED performed data analyses. VK wrote the manuscript. All authors read, critically revised, and approved the final manuscript.

\section{Competing interests}

The authors have declared that no competing interests exist.

\section{Acknowledgements}

We thank Sonja von Serényi, Jennifer Wipperfürth, and Roswitha Davtalab for excellent technical assistance. We also thank the gynecologists and the pathologists from PATH Foundation's cooperating breast cancer centers in Germany for their help in allocating samples (PD Dr. Georg Kunz, Dr. Claus Langwieder, Dr. August Dygkers, Dr. Martin Rees, Dortmund; Prof. Dr. Thomas Dimpfl, Prof. Dr. Irina Berger, Kassel; Prof. Dr. Ute-Susann Albert, Dr. Annette Ramaswamy, Marburg; Prof. Dr. Christian Jackisch, Dr. Susanne Braun, Offenbach).

\section{Author details}

${ }^{1}$ Molecular Oncology Group, Institute of Pathology, Medical Faculty of the RWTH Aachen University, Pauwelsstrasse 30, D-52074 Aachen, Germany. 2Department of Gynecology and Obstetrics, University Hospital Erlangen, Universitätsstrasse 21-23, D-91054 Erlangen, Germany. ${ }^{3}$ Patients' Tumor Bank of Hope (PATH) Foundation, Schäftlarnstr. 62, D-81337 München, Germany. ${ }^{4}$ Department of Pathology, University of Erlangen, Krankenhausstrasse 12, D91054 Erlangen, Germany.

Received: 31 August 2012 Revised: 5 December 2012

Accepted: 9 January 2013 Published: 15 January 2013

\section{References}

1. Jemal A, Bray F, Center MM, Ferlay J, Ward E, Forman D: Global cancer statistics. CA Cancer J Clin 2011, 61:69-90.

2. Etzioni R, Urban N, Ramsey S, McIntosh M, Schwartz S, Reid B, Radich J, Anderson G, Hartwell L: The case for early detection. Nat Rev Cancer 2003, 3:243-252.

3. Armstrong K, Moye E, Williams S, Berlin JA, Reynolds EE: Screening mammography in women 40 to 49 years of age: a systematic review for the American College of Physicians. Ann Intern Med 2007, 146:516-526.

4. Berg WA: Tailored supplemental screening for breast cancer: what now and what next? AJR Am J Roentgenol 2009, 192:390-399.

5. Houssami N, Ciatto S, Irwig L, Simpson JM, Macaskill P: The comparative sensitivity of mammography and ultrasound in women with breast symptoms: an age-specific analysis. Breast 2002, 11:125-130.

6. Hooley RJ, Andrejeva L, Scoutt LM: Breast cancer screening and problem solving using mammography, ultrasound, and magnetic resonance imaging. Ultrasound Q 2011, 27:23-47.

7. Leon SA, Shapiro B, Sklaroff DM, Yaros MJ: Free DNA in the serum of cancer patients and the effect of therapy. Cancer Res 1977, 37:646-650.

8. Jahr S, Hentze H, Englisch S, Hardt D, Fackelmayer FO, Hesch RD, Knippers R: DNA fragments in the blood plasma of cancer patients: quantitations and evidence for their origin from apoptotic and necrotic cells. Cancer Res 2001, 61:1659-1665.

9. Hoque MO, Feng Q, Toure P, Dem A, Critchlow CW, Hawes SE, Wood T, Jeronimo C, Rosenbaum E, Stern J, Yu M, Trink B, Kiviat NB, Sidransky D: Detection of aberrant methylation of four genes in plasma DNA for the detection of breast cancer. J Clin Oncol 2006, 24:4262-4269.

10. Dulaimi E, Hillinck J, Ibanez dC, Al-Saleem T, Cairns P: Tumor suppressor gene promoter hypermethylation in serum of breast cancer patients. Clin Cancer Res 2004, 10:6189-6193.

11. Radpour R, Barekati Z, Kohler C, Lv Q, Burki N, Diesch C, Bitzer J, Zheng H, Schmid S, Zhong XY: Hypermethylation of tumor suppressor genes involved in critical regulatory pathways for developing a blood-based test in breast cancer. PLoS One 2011, 6:e16080.

12. Brooks JD, Cairns P, Shore RE, Klein CB, Wirgin I, Afanasyeva Y, ZeleniuchJacquotte A: DNA methylation in pre-diagnostic serum samples of breast cancer cases: results of a nested case-control study. Cancer Epidemiol 2010, 34:717-723.

13. Laird PW: The power and the promise of DNA methylation markers. Nat Rev Cancer 2003, 3:253-266.

14. Radpour R, Barekati Z, Kohler C, Holzgreve W, Zhong XY: New trends in molecular biomarker discovery for breast cancer. Genet Test Mol Biomarkers 2009, 13:565-571.

15. Brooks J, Cairns P, Zeleniuch-Jacquotte A: Promoter methylation and the detection of breast cancer. Cancer Causes Control 2009, 20:1539-1550. 
16. Lee BB, Lee EJ, Jung EH, Chun HK, Chang DK, Song SY, Park J, Kim DH: Aberrant methylation of APC, MGMT, RASSF2A, and Wif-1 genes in plasma as a biomarker for early detection of colorectal cancer. Clin Cancer Res 2009, 15:6185-6191.

17. Huang KT, Dobrovic A, Yan M, Karim RZ, Lee CS, Lakhani SR, Fox SB: DNA methylation profiling of phyllodes and fibroadenoma tumours of the breast. Breast Cancer Res Treat 2010, 124:555-565.

18. Veeck J, Chorovicer M, Naami A, Breuer E, Zafrakas M, Bektas N, Durst M, Kristiansen G, Wild PJ, Hartmann A, Knuechel R, Dahl E: The extracellular matrix protein ITIH5 is a novel prognostic marker in invasive nodenegative breast cancer, and its aberrant expression is caused by promoter hypermethylation. Oncogene 2008, 27:865-876.

19. Suzuki H, Toyota M, Carraway H, Gabrielson E, Ohmura T, Fujikane T, Nishikawa N, Sogabe Y, Nojima M, Sonoda T, Mori M, Hirata K, Imai K, Shinomura $Y$, Baylin SB, Tokino T: Frequent epigenetic inactivation of Wnt antagonist genes in breast cancer. Br J Cancer 2008, 98:1147-1156.

20. Veeck J, Bektas N, Hartmann A, Kristiansen G, Heindrichs U, Knuchel R, Dahl E: Wnt signalling in human breast cancer: expression of the putative Wnt inhibitor Dickkopf-3 (DKK3) is frequently suppressed by promoter hypermethylation in mammary tumours. Breast Cancer Res 2008, 10:R82.

21. Yan PS, Shi H, Rahmatpanah F, Hsiau TH, Hsiau AH, Leu YW, Liu JC, Huang TH: Differential distribution of DNA methylation within the RASSF1A CPG island in breast cancer. Cancer Res 2003, 63:6178-6186.

22. Ai L, Tao Q, Zhong S, Fields CR, Kim WJ, Lee MW, Cui Y, Brown KD, Robertson KD: Inactivation of Wnt inhibitory factor-1 (WIF1) expression by epigenetic silencing is a common event in breast cancer. Carcinogenesis 2006, 27:1341-1348.

23. Patients' Tumor Bank of Hope Foundation. [http://www.stiftungpath.org/].

24. Herman JG, Graff JR, Myohanen S, Nelkin BD, Baylin SB: Methylationspecific PCR: a novel PCR assay for methylation status of CpG islands. Proc Natl Acad Sci USA 1996, 93:9821-9826.

25. Ogino S, Kawasaki T, Brahmandam M, Cantor M, Kirkner GJ, Spiegelman D, Makrigiorgos GM, Weisenberger DJ, Laird PW, Loda M, Fuchs CS: Precision and performance characteristics of bisulfite conversion and real-time PCR (MethyLight) for quantitative DNA methylation analysis. J Mol Diagn 2006, 8:209-217.

26. Galm O, Herman JG: Methylation-specific polymerase chain reaction. Methods Mol Med 2005, 113:279-291.

27. Zweig MH, Campbell G: Receiver-operating characteristic (ROC) plots: a fundamental evaluation tool in clinical medicine. Clin Chem 1993, 39:561-577.

28. Eads CA, Danenberg KD, Kawakami K, Saltz LB, Blake C, Shibata D, Danenberg PV, Laird PW: MethyLight: a high-throughput assay to measure DNA methylation. Nucleic Acids Res 2000, 28:E32.

29. Lehmann U, Langer F, Feist H, Glockner S, Hasemeier B, Kreipe H: Quantitative assessment of promoter hypermethylation during breast cancer development. Am J Pathol 2002, 160:605-612.

30. Donninger $\mathrm{H}$, Vos MD, Clark GJ: The RASSF1A tumor suppressor. J Cell Sci 2007, 120:3163-3172

31. Van De Voorde V, Speeckaert R, Van Gestel D, Bracke M, De Neve W, Delanghe J, Speeckaert M: DNA methylation-based biomarkers in serum of patients with breast cancer. Mutat Res 2012, 751:304-325.

32. Taback B, Giuliano AE, Lai $R$, Hansen N, Singer FR, Pantel K, Hoon DS: Epigenetic analysis of body fluids and tumor tissues: application of a comprehensive molecular assessment for early-stage breast cancer patients. Ann N Y Acad Sci 2006, 1075:211-221.

33. Kim JH, Shin MH, Kweon SS, Park MH, Yoon JH, Lee JS, Choi C, Fackler MJ, Sukumar S: Evaluation of promoter hypermethylation detection in serum as a diagnostic tool for breast carcinoma in Korean women. Gynecol Oncol 2010, 118:176-181.

34. Jing F, Yuping $W$, Yong $C$, Jie $L$, Jun $L$, Xuanbing $T$, Lihua $H: C p G$ island methylator phenotype of multigene in serum of sporadic breast carcinoma. Tumour Biol 2010, 31:321-331.

35. Mandelson MT, Oestreicher N, Porter PL, White D, Finder CA, Taplin SH, White E: Breast density as a predictor of mammographic detection: comparison of interval- and screen-detected cancers. J Natl Cancer Inst 2000, 92:1081-1087.

36. McCormack VA, dos Santos Silva I: Breast density and parenchymal patterns as markers of breast cancer risk: a meta-analysis. Cancer Epidemiol Biomarkers Prev 2006, 15:1159-1169.
37. Boyd NF, Guo H, Martin LJ, Sun L, Stone J, Fishell E, Jong RA, Hislop G, Chiarelli A, Minkin S, Yaffe MJ: Mammographic density and the risk and detection of breast cancer. N Engl J Med 2007, 356:227-236.

38. Byrne C, Schairer C, Wolfe J, Parekh N, Salane M, Brinton LA, Hoover R, Haile R: Mammographic features and breast cancer risk: effects with time, age, and menopause status. J Natl Cancer Inst 1995, 87:1622-1629.

39. Shaw JA, Page K, Blighe K, Hava N, Guttery D, Ward B, Brown J, Ruangpratheep C, Stebbing J, Payne R, Palmieri C, Cleator S, Walker RA, Coombes RC: Genomic analysis of circulating cell-free DNA infers breast cancer dormancy. Genome Res 2012, 22:220-231.

40. Board RE, Wardley AM, Dixon JM, Armstrong AC, Howell S, Renshaw L, Donald E, Greystoke A, Ranson M, Hughes A, Dive C: Detection of PIK3CA mutations in circulating free DNA in patients with breast cancer. Breast Cancer Res Treat 2010, 120:461-467.

41. Sobin LH, Wittekind Ch: TNM Classification of Malignant Tumours. New York: Wiley; 51997.

42. Elston EW, Ellis IO: Method for grading breast cancer. J Clin Pathol 1993, 46:189-190.

43. Remmele W, Stegner HE: Recommendation for uniform definition of an immunoreactive score (IRS) for immunohistochemical estrogen receptor detection (ER-ICA) in breast cancer tissue. Pathologe 1987, 8:138-140.

doi:10.1186/bcr3375

Cite this article as: Kloten et al:: Promoter hypermethylation of the tumor-suppressor genes ITIH5, DKK3, and RASSF1A as novel biomarkers for blood-based breast cancer screening. Breast Cancer Research 201315 : R4.

\section{Submit your next manuscript to BioMed Central and take full advantage of:}

- Convenient online submission

- Thorough peer review

- No space constraints or color figure charges

- Immediate publication on acceptance

- Inclusion in PubMed, CAS, Scopus and Google Scholar

- Research which is freely available for redistribution

Submit your manuscript at www.biomedcentral.com/submit
C) Biomed Central 